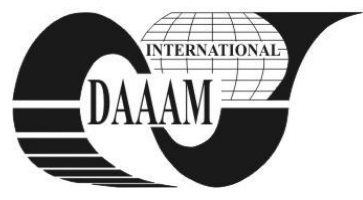

Annals of DAAAM for 2011 \& Proceedings of the 22nd International DAAAM Symposium, Volume 22, No. 1, ISSN 1726-9679 ISBN 978-3-901509-83-4, Editor B. Katalinic, Published by DAAAM International, Vienna, Austria, EU, 2011 Make Harmony between Technology and Nature, and Your Mind will Fly Free as a Bird Annals \& Proceedings of DAAAM International 2011

\title{
MODELING INDUCTIVE HEATING PROCESS OF A CYLINDRICAL STRUCTURE MODE OF TWO DIFFERENT MATERIALS AT A FRECQUENCY OF 1000HZ
}

\author{
HOBLE, D[orel] A[nton]; STASAC, C[laudia] O[limpia]; BANDICI, L[ivia] \& MOLNAR, C[armen] O[tilia]
}

\begin{abstract}
The paper refers to a technology of achieving bimetallic combination by processing structure in an electromagnetic field of medium frequency. The numerical model used in this study is based on the finite element model and is destined to the study of heating by induction in volume of cylindrical feromagnetic steel structure whose properties vary with temperature and suffer phase transformation at Curie point.
\end{abstract}

Key words: cleating, electromagnetic field, inductive heating, heating process bimetallic components

\section{INTRODUCTION}

The cleating technology of two materials is based on the exterior structure heating up to $803^{\circ} \mathrm{C}$, then the inductor feeding is stopped. The interior cylindrical feeding is stopped. The interior cylindrical structure is introduced, the transfer of heat towards the assembly interior being realized through three phenomena of thermic conduction (Staşac \& Hoble, 2008).

Due to the expanding of the exterior structure, during the inductive heating process, its interior diameter will grow, allowing the introduction in this phase of an interior cyllindrical structure, Fig. 1. At the cooling of the exterior structure, by thermic transfer towards the interior one, this is contracted, causing pressure to the interior one. Due to this fact, a pressure force of exterior structure to the interior one appears, which in the case of a well controlled process leads to the structural combination of the two materials.

For the study carried out in this paper an assembly made up of two pieces of cylindrical shape, empty inside and coaxially assembled, the structure of the piece being presented below Fig. 2. The inside element is made up of brass and the exterior one of iron. Two materials were chosen, steel and brass to allow for further study towards the combination of the hybrid structures, using the electromagnetic processing.

The technology of combination of the two materials is based on the structure heating towards the exterior structure up to a certain temperature, after that the inductor energy supply is stopped, the transfer of the heating towards the assembly interior producing the thermic conduction phenomenon.

Due to the different expanding index a pressure force of the interior structure to the exterior structure appears which in the case of the well controlled process leads to the structural combination of the two materials.

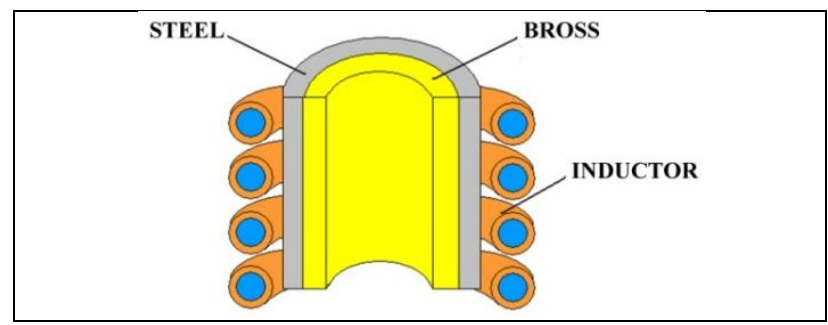

Fig. 1. Modelled structure

\section{PRESENTATION OF THE STUDY CASE}

For the study carried out in this paper an assembly made up of two pieces of cylindrical shape, empty inside and coaxially assembled, the structure of the piece being presented below Fig. 2. The inside element is made up of brass and the exterior one of iron. Two materials were chosen, steel and brass to allow for further study towards the combination of the hybrid structures, using the electromagnetic processing.

The technology of combination of the two materials is based on the structure heating towards the exterior structure up to a certain temperature, after that the inductor energy supply is stopped, the transfer of the heating towards the assembly interior producing the thermic conduction phenomenon.

Due to the different expanding index a pressure force of the interior structure to the exterior structure appears which in the case of the well controlled process leads to the structural combination of the two materials (Hoble \& Staşac, 2008). The main phases in building space geometry in the calculation area are presented in Fig. 3, the classical procedure implying the points construction, then the lines and regions of surface type.

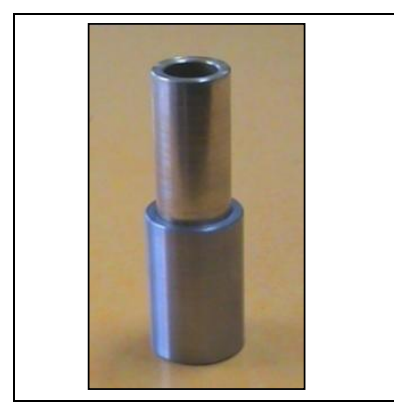

Fig. 2. The pieces to be processed

Fig. 3. Geometry of the calculation field

\section{THE NUMERICAL MODELING}

To achieve numerical modeling program was used the modeling and simulation program FLUX 2D, and input power and energy density of $20 \mathrm{~A} / \mathrm{mm}^{2}$ and frequency of $1000 \mathrm{~Hz}$

After numerical simulation, the repartition of the magnetic field density was studied, the simulation result being presented in Fig. $4 a$.
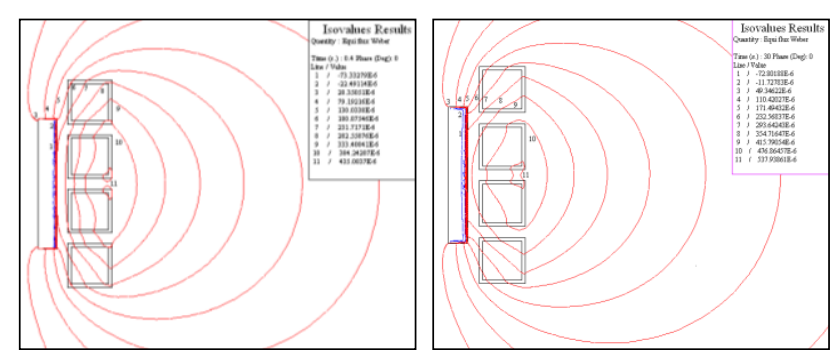

Fig. 4a. Magnetic field lines at Fig. 4b. Magnetic field lines at 
$0,4 \mathrm{~s}$ and frequency $1000 \mathrm{~Hz} \quad 30 \mathrm{~s}$ and frequency $1000 \mathrm{~Hz}$

The distribution of the temperature field, in the heated piece, represents one of the most important parameters that were followed during the study, Fig.5. That is why we will present the results obtained after modeling and simulation of the heating process (Hantila, \& Vasiliu 2005). To maintain the possibility of results comparison the time steps where analysis was made are $1 \mathrm{~s}$ and $30 \mathrm{~s}$.
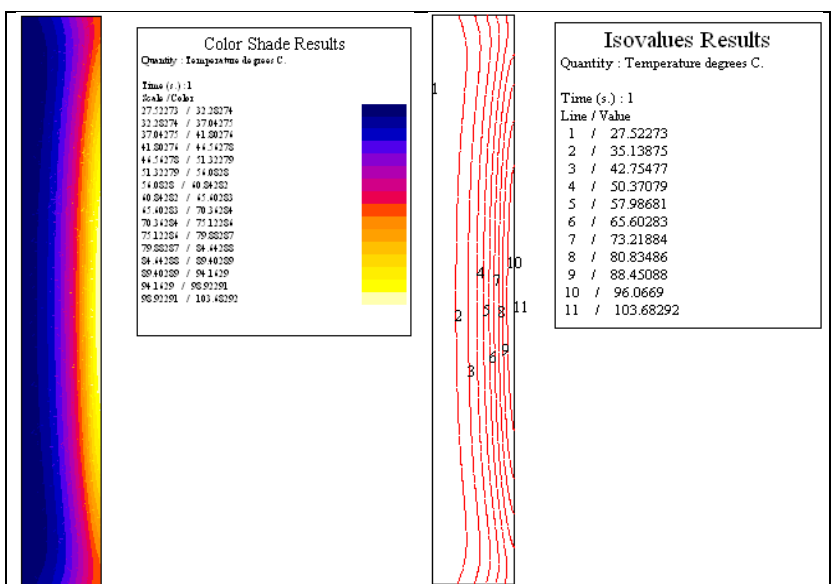

Fig. 5a. Distribution of thermic Fig. 5b. Distribution of field at time moment $1 \mathrm{~s}$ and thermic field lines at time work frequency $1000 \mathrm{~Hz}$ moment $1 \mathrm{~s}, 1000 \mathrm{~Hz}$
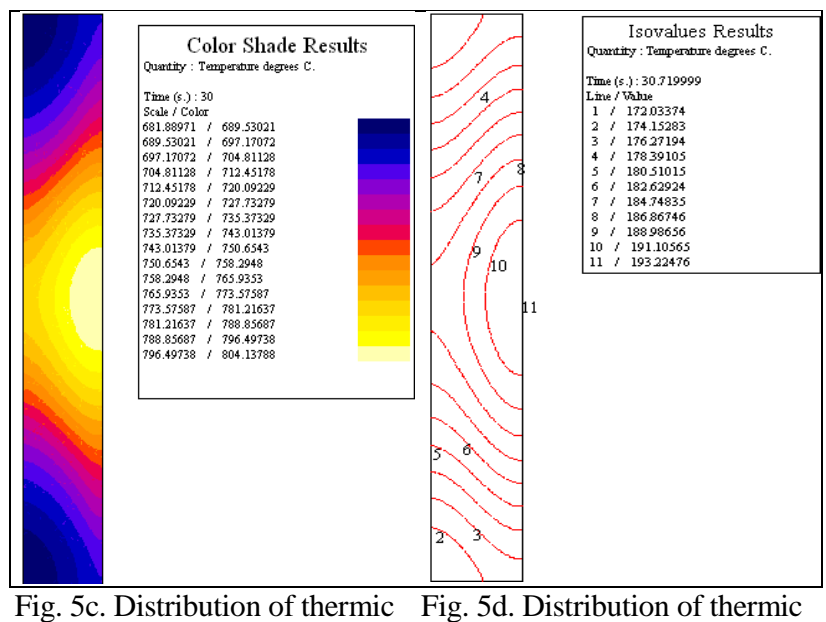

Fig. 5c. Distribution of thermic Fig. 5d. Distribution of thermic field at time moment $30 \mathrm{~s}$ and field lines at time moment $30 \mathrm{~s}$ work frequency $1000 \mathrm{~Hz} \quad$ and work frequency $1000 \mathrm{~Hz}$

In this study analyzed the eddy current heating and expansion of the outer pipe diameters for the achievement gap necessary to produce the cleating process.

The temperature field in this piece was obtained by solving the problems linked to quasistationary and thermic diffusion electromagnetic field, Fig.6.

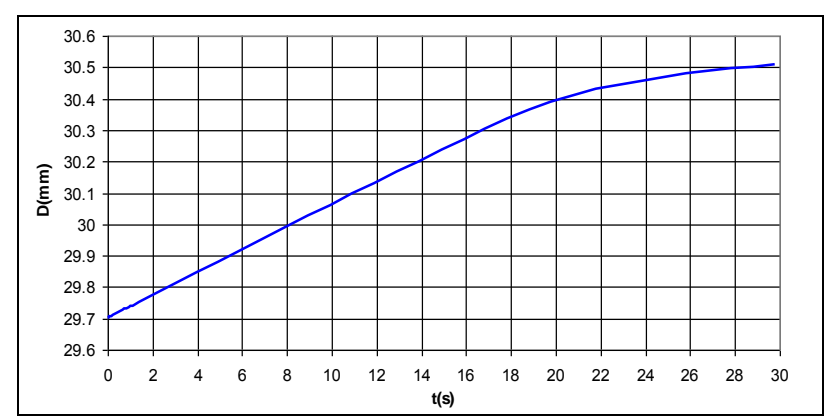

Fig. 6. The inner diameter of outer pipe
The heating is made at a high enough temperature $\left(803^{\circ} \mathrm{C}\right)$, so that the expanding leads to such a diameter difference that allows the introduction of the interior pipe in the exterior one, even if during the handling the temperature of the exterior pipe decreases, (Hantila, 2004).

The value of the binding (fitting) diameter is reached over approximately $16.4 \mathrm{~s}$.

\section{CONCLUSIONS}

The results obtained above show that the analysis put forward within this paper enables the adopting of the most convenient work frequency and of the values of the current density. In the hypothesis that the frequency increases too much, it is likely that the pellicle effect to be that marked, that during the short time of applying the current, the temperature in certain areas of the part to increase very much, the average temperature remaining insufficiently high for analysing the cleating diameter.

The above results show that the analysis proposed in this paper allows the adoption of the most convenient work frequency and values of the current density. The hypothesis that the frequency increases too much it is possible that the pellicles effect can be so pronounced that is a short time after the current appliance the temperature in certain areas of the piece increase a lot, the average temperature remaining insufficient to achieve the cleating diameter

The mechanic bindings through thermic processes (fitting) are often used in the practical applications, that is why it was highly necessary the analysing of the process of heating by induction of certain metallic parts, in view of optimizing the phenomenon of electro-magnetic conversion and distribution of the electro-magnetic field, coupled with the thermic one in the structures subject to heating.

Extension of research for the next period will focus on inductive heating and complex shapes (square, hexagon), where the effect comes through.

\section{ACKNOWLEDGEMENTS}

This work was cofinanced from the European Social Fund through Sectoral Operational Programme Human Resources Development 2007-2013, project number POSDRU/ $89 / 1.5 / \mathrm{S} / 56287$ „Postdoctoral research programs at the forefront of excellence in Information Society technologies and developing products and innovative processes", partner University of Oradea.

\section{REFERENCES}

Hantila, F. (2004). The magnetic field in permanent magnets structures , Ed. Electra, Bucureşti, ISBN 973-7728-22-X

Hantila, F. \& Vasiliu, M. (2005). The electromagnetic field variable in time, Ed. Electra, Bucureşti

Staşac, C.O. \& Hoble, D.A. (2008). Modelling of the electromagnetic field in bimetallic components, Journal of Electrical and Electronics Engineering, Oradea, pp. 134136

Staşac, C.O. \& Hoble, D.A. (2008). The study of modelling inductive heating utilization the joining technique of cleating, Journal of Electrical and Electronics Engineering, Oradea, 2008, pp. 137-139

J.C. Bourhis (1996). Chauffage de billettes par inducteur multicouche: Du prototype a la premiere reference industrielle, Les cahiers de l ingeniere, No 62, 1996 